\title{
CORRIGENDUM
}

\section{Possible links between long-term geomagnetic variations and whole-mantle convection processes}

\author{
A. J. Biggin, B. Steinberger, J. Aubert, N. Suttie, R. Holme, T. H. Torsvik, D. G. van der Meer and D. J. J. van Hinsbergen \\ Published online: 29 July 2012 | http://dx.doi.org/10.1038/ngeo1521
}

In the print version of this Review article, some labelling in Figs 3, 4a and $5 \mathrm{c}$ is incorrect: in Fig. 3 the label 'Laurrassia and Gondwana collide' is incorrectly placed; in Fig. 4a some axes labels were incorrect; in Fig. $5 \mathrm{c}$ the Greek $\delta$ symbol has printed incorrectly. All figures are correct online. 